\title{
Effect of Educational Program on Elementary School Teachers' Knowledge, Attitude, and Classroom Management Techniques Regards Attention Deficit Hyperactivity Disorder
}

\author{
Asmaa Mohammed Ali Alabd ${ }^{1}$, Soha Kamel Mesbah² \& Mohammad Alboliteeh ${ }^{3}$ \\ ${ }^{1}$ Psychiatric and Mental Health Nursing, Faculty of Nursing, Benha University, Egypt \\ ${ }^{2}$ Community Health Nursing, Faculty of Nursing, Benha University, Egypt \\ ${ }^{3}$ University of Hail, Saudi Arabia \\ Correspondence: Asmaa Mohammed Ali Alabd, Psychiatric and Mental Health Nursing, Faculty of Nursing, \\ Benha University, Egypt.
}

Received: November 22, 2018

Accepted: December 13, 2018 Online Published: December 26, 2018

doi:10.20849/ijsn.v3i3.528

URL: https://doi.org/10.20849/ijsn.v3i3.528

\begin{abstract}
Background: Attention deficit hyperactivity disorder (ADHD) is the most common neurobehavioral disorder of childhood and can profoundly affect the academic achievement, well-being, and social interactions of children. Teachers play an important role in the diagnosis of ADHD because of their daily contact with students in a range of pertinent situations. Aim of the study: Evaluate the effect of educational program on knowledge, attitude and classroom management technique among elementary school teachers in Hail City towards attention deficit hyperactivity disorder. A quasi-experimental design was used to conduct the current study in four Saudi elementary school in Hail City ( 2 females \& 2 males elementary school) during the period from March 2018 to May 2018. Subjects: A sample of convenience of 95 teachers working in the previously elementary school. Tools: One tool were utilized for data collection, Self-administrated Questionnaire: The tool was divided into four parts, I) personal characteristics of studied sample, II) the knowledge of Attention Deficit Disorders Scale (KADDS), III) Teachers' beliefs about and attitudes toward ADHD, and IV) Perception of classroom management techniques. Results: Findings showed that mean score regarding ADHD knowledge, attitude, and classroom management technique were significantly higher after than before program with highly significant association between knowledge, attitude, and classroom management technique. Conclusion: ADHD educational program was effective in improving teachers' knowledge, attitude, and classroom management technique. Recommendation: The results indicated the need to increase awareness about ADHD and importance of adopting classroom management technique in order to deal with ADHD children through health education programs to teachers were needed.
\end{abstract}

Keywords: ADHD, classroom management technique, educational program

\section{Introduction}

Attention Deficit Hyperactivity Disorder (ADHD) is reportedly the most pervasive disorder of childhood affecting approximately $3 \%$ to $5 \%$ of school-aged children with prevalence rates increasing significantly over the past two decades. Children had ADHD presents a persistent pattern of behaviors of inattention, motor over-activity, and/or impulsivity. Inattention may manifest in social, occupational, and academic settings. Symptoms include difficulty with sustained attention, being unable to complete tasks, not following through on instructions and requests, and inability to complete duties and school home work. Symptoms of hyperactivity include fidgeting, inability to sit still in classroom settings, being always "on the go," and talkative, while a symptom of impulsivity is difficulty waiting their turn role (American Psychiatric Association, 2013; Patidar et al., 2016).

Symptoms of ADHD can be mistaken for emotional or disciplinary problems or missed entirely in quiet, well-behaved children, leading to a delay in diagnosis (Krull, 2017). According to Diagnostic and Statistical Manual of Mental Disorders 4th edition (DSM-IV), three subtypes of the attention deficit hyperactivity disorder (ADHD) are predominantly inattentive, predominantly hyperactive-impulsive, and combined types (Bradshaw \& Madeeha, 2013). 
No one knows exactly what causes ADHD, but certain things are known to play a role, although a combination of factors is thought to be responsible as genetic, organic, and environmental factors (Thapar et al., 2012).Studies show that if a parent has ADHD, a child has more than a 50\% chance of having it. If an older sibling has it, a child has more than a $30 \%$ chance or pregnant women who smoke or drink alcohol. Although it's been discussed, research does not present that ADHD is linked to eating too much sugar or watching a lot of T.V. (Bhandari, 2017).

While there is no cure for ADHD, currently available treatments can help decrease symptoms and improve functioning. Treatments include medication, psychotherapy, education or training, or a combination of treatments (National Institution of Mental Health, 2016).

As children spend most of their time in schools and interact with teachers in a many of ways on a daily basis. So, the school plays a very important role in the detecting of children with ADHD. It has been affirmed that teachers detect children with ADHD more frequently than do parents or physicians (Perold, Louw and Kleynhans, 2010; Arnett, MacDonald, \& Pennington, 2013). Teachers play central roles in reporting symptoms, advising parents to seek assessment, and assisting children with ADHD to achieve academically and socially. Also, teachers are often responsible for implementing and evaluating interventions for ADHD in the classroom (Andreson et al., 2012; Jimoh, 2014).

Teachers who are successful in educating children with ADHD use a three-pronged strategy. They begin by identifying the unique needs of the child, and then select different educational practices associated with academic instruction, behavioral interventions, and classroom accommodations that are appropriate to meet that child's needs (Bhandari, 2017). The classroom strategies include that teachers create a focus for children with ADHD by implementing several structures into their daily practice as the use of a regular timetable, the presentation of new material in a step-by-step manner and the provision of short, clear instructions (HADD support Group, 2017).

School nurses are in a unique position and an integral part in the process of increasing awareness about ADHD through improving the service delivery model for affected children and their families. There is a strong foundation of research on which they can build to improve the benefits through study, workshops, community programs, and national screening programs (ALBashtawy et al., 2015; Khamaiseh \& ALBashtawy, 2015). Also, school nurses are the bridge connecting health and learning and provide care coordination for students diagnosed with ADHD to optimize learning. "Effective communication and collaboration among school nurses and pediatric-focused advanced practice registered nurses (APRNs) enable student-centered care and solutions (Bascuas, 2016).

\section{Significance of the Study}

Adults with undiagnosed ADHD may have a history of poor academic performance, problems at work, or difficult or failed relationships. SO, it is helpful for children to be diagnosed, or for families to have their child diagnosed with ADHD / receive treatment and for teachers to manage children diagnosed with ADHD and uses coping strategies in classroom. The Substance Abuse and Mental Health Services Administration (2012) reported that about 5\% to $9 \%$ of children between the ages of 9 and 17 experience serious emotional and behavioral disturbances that may affect their ability to function at home, in school, or in the community. ADHD is a multifaceted disease characterized by the core symptoms of hyperactivity, inattention, and impulsivity, affecting children across every socioeconomic, ethnic, and regional group an estimated $40 \%$ to $60 \%$ of children with ADHD have comorbidities such as anxiety, depression, and learning disabilities (Barkley, 2014).

\section{Aim of the Study}

The study aimed to evaluate the effect of educational program on knowledge, attitude and classroom management technique among elementary school teachers in Hail City towards attention deficit hyperactivity disorder.

\section{Research Hypothesis}

The study supposed the following hypothesis:

1. Elementary school teachers' knowledge, attitude and classroom management techniques at post educational program is better than pre educational program.

2. There is a relationship between post educational program knowledge scores and selected personal characteristics of elementary schools' teachers

3. There is a significant positive correlation between post educational program scores of teachers' knowledge, attitudes and their perception of classroom management techniques 


\section{Subject and Methods}

Design: Quasi experimental design was utilized to conduct the current study.

Setting: The study was conducted at 4 Saudi elementary school in Hail City, Saudi Arabia (2 females \& 2 males elementary school).

Sample: A Convenient sampling technique was used. All teachers working in the previously elementary school and accepted to participate were included in this study. A total number was 95 (53 male \& 42 female) with following inclusion criteria: Both sex was involved, and teachers who are more contact with children and accept to participate and teachers who are absent to attend two sessions were excluded from the study.

Tools: One tool were used for data collection

Tool (I): Self-administrated Questionnaire: It was divided into four parts.

Part one: personal characteristics of studied sample as age, sex, grade, teaching experience, marital status, and educational level years of experience about ADHD and taking any workshop about ADHD.

Part two: The Knowledge of Attention Deficit Disorders Scale (KADDS) developed by (Sciutto et al., 2000): to measure teachers' knowledge and misperceptions of Attention-Deficit/Hyperactivity Disorder. Items in the KADDS questionnaire phrased as statements about ADHD with three option response format: true (T), false (F) or don't know (DK). These items divided into three specific areas: symptoms/diagnosis of ADHD (9 items), the treatment of ADHD (12 items), and general knowledge about the nature, causes and outcome of ADHD (15 items). The KADDS format allows for the differentiation between what teachers do not know from their misperception of ADHD (Sciutto et al., 2000; Soroa et al., 2013).

The correct answer of questions $(3,4,5,6,8,9,10,13,15,16,17,20,21,25,26,31,32$, and 33$)$ is true and the correct answer of questions $(1,2,7,11,12,14,18,19,22,23,24,27,28,29,30,34,35$, and 36) is false. Teachers' knowledge was calculated for each items as follow: correct answer was scored (1 point) while incorrect answer or don't know was scored (zero point). The total score for all questions related to knowledge was 36 points which represent $100 \%$ and categorized into three levels as the following: poor if knowledge less than $60 \%$, average knowledge from $60->75 \%$ and good if knowledge more than $<75 \%$.

Part 3: Assessed teachers' beliefs about and attitudes toward ADHD by Youssef et al., (2015): to assess teachers' beliefs about and attitudes toward ADHD by the use of 25 statements. A 5-point Likert type scale was used in this section with teachers indicating whether they agreed, strongly agreed, neither agreed, nor disagreed, disagreed, or strongly disagreed with the statement. Several items were again reversing scored to ensure conscious completion of the questionnaires. The scoring system about teachers' total attitude was considered positive if the score was more than $75 \%$, uncertain attitude if the score $60->75 \%$, and negative attitude if score less than $60 \%$.

Part 4: Perception of classroom management techniques by (DuPaul \& Weyandt, 2006; Raggi \& Chronis, 2006): to assess teachers' perceptions of how children who have been diagnosed with ADHD ought to be managed in the classroom. It was contained 13 items, which were self-constructed, based on a review of the literature. Participants responded to items in the classroom management section on a four-point Likert-type scale ranging from $1=$ strongly disagree, to $4=$ strongly agree. In the data analysis process, the items were recorded to $1=$ disagree, and $2=$ agree. Teacher's total perception of classroom management techniques scoring system was considered high if the score more than $75 \%$, moderate if the score $60->75 \%$, and low if the score less than $60 \%$.

\section{Methods of Data Collection}

\subsection{Tool Validity and Reliability}

The content validity was done through five experts in psychiatric and community nursing for face and content validity, and their opinions were requested via an assessment form. The experts were asked to grade each item as essential," "useful but inadequate" or "unnecessary". Modification was carried out according to the expert's judgment on the clarity of sentences and appropriateness of content. The KADDS is considered to be "one of the most widely used instruments to assess the level of knowledge of teachers regarding ADHD, and is the first instrument whose indices of reliability and validity were published in this field". Internal consistency of the KADDS total score, in previous studies, has ranged from 0.82 to 0.89 (Sciutto et al., 2000; Herbert et al., 2004; Soroa et al., 2013). Cronbach's alpha value for the current study was 0.76 which indicate an adequate internal consistency. 


\subsection{Pilot Study}

A pilot study was carried out on a sample of 10 teachers and were excluded from the study sample. The aim of the pilot was to test the feasibility and clarity of the study tools. It also helped to detect the time needed for filling up the sheets. The time needed to fill out the sheet in one session was 25-30 minutes. Following the pilot study, the questionnaire was finalized and made ready for use.

\subsection{Ethical Consideration}

This study was conducted under the approval of the Faculty of Nursing Ethics Committee, Hail University. An explanation about the purpose of the study was given to participants, and they were also informed that they could withdraw from the study at any time before the completion of the study. After agreement for Participation in the study, participants were asked for oral consent. Moreover, they were reassured that all information gathered would be confidential and used only for the purpose of the study.

\subsection{Field of Work}

\subsubsection{Data Were Collected in the Following Sequence}

- An official permission to carry out the study was obtained from pertinent authorities after explanation of its purpose. Then, structured interview was conducted for teachers eligible for the study (fulfilled the inclusion and exclusion criteria) in order to explain the purpose of the study, assure confidentiality and to obtain informed oral consent.

- Data collection extended over a period of three months from March 2018 to May 2018, and data was collected for two days weekly from $9 \mathrm{am}$ to $1 \mathrm{pm}$.

\subsection{Procedures}

The program comprised the following phases:

\subsubsection{A- Assessment Phase}

Each teacher was interviewed before applying the planned program to collect the baseline teacher's data using all study tools. This interview took about 25 to 30 minutes.

\subsubsection{B- Implementation Phase}

The developed program was implemented for the studied teachers in the school classroom. It was conducted in 4 sessions, which was implemented during their leisure time. The first session was carried out during assessment phase, involved (overview about ADHD) and the second session involved (Definition, and causes) while the third involved (signs, symptoms, diagnosis, and ADHD effect), and fourth session involved (Treatment and classroom management technique). Each session took about 30 to 35 minutes. The instructional booklet was given to each teacher under the study to help for reviewing and support teaching at home.

The program was developed by the researcher based on review of current literature. A booklet containing the content of the program, it was written in a simple Arabic language and supplemented by photos and illustrations to help the teachers understanding of the content involved: definition of ADHD, causes, signs, symptoms, diagnosis, ADHD effect, treatment and classroom management technique.

Suitable teaching aids prepared specially for the program were: booklet, flipchart, video and real situations. At the end of every session, teachers' questions were discussed to correct any misunderstanding, which has been happened.

To ensure that the teachers understand the program content, each session was started by a summary about what was given through the previous one and objectives of the new one were mentioned taking into consideration using simple language to suit all teachers. To ensure exposure of all subjects to the same learning experience all teachers received the same protocol content using the same teaching methods.

\subsubsection{C- Evaluation Phase}

Immediately after implementation of the program, each teacher in the study was interviewed to evaluate knowledge using the tool (part II, III, and IV).The results were compared to the pre-test results.

\subsection{Statistical Analysis}

Statistical analysis was done using SPSS-22 statistical software package and Excel for figures. Data were presented using descriptive statistics in the form of frequencies and percentages for qualitative variables, and means and standard deviations for quantitative variables. Quantitative continuous data were compared by using student T-test in case of comparisons between the mean scores of the studied groups. Qualitative studied 
variables were compared using Chi-square test. Statistical significance was considered at $\mathrm{P}$ value $<0.05$.

\section{Results}

Table 1. Distribution of the studied sample according to their personal characteristics $(\mathrm{n}=95)$

\begin{tabular}{|c|c|c|}
\hline Items & NO. (95) & $\%$ \\
\hline \multicolumn{3}{|l|}{ - Sex: } \\
\hline Male & 53 & 55.8 \\
\hline Female & 42 & 44.2 \\
\hline \multicolumn{3}{|l|}{ - Age : } \\
\hline From $20-30$ years & 18 & 18.9 \\
\hline From $31-40$ years & 62 & 65.3 \\
\hline From $41-50$ years & 10 & 10.5 \\
\hline From 51-60 years & 5 & 5.3 \\
\hline Mean \& SD & & $45.82 \pm 8.35$ \\
\hline \multicolumn{3}{|l|}{ - Educational levels: } \\
\hline Diploma & 2 & 2.1 \\
\hline Bachelor's degree & 86 & 90.5 \\
\hline Highly educational level & 7 & 7.4 \\
\hline \multicolumn{3}{|l|}{ - Marital status: } \\
\hline Married & 91 & 95.8 \\
\hline Single & 4 & 4.2 \\
\hline \multicolumn{3}{|c|}{ - Years of experience: } \\
\hline Less than 5 years & 29 & 30.5 \\
\hline From 5-10 years & 27 & 28.4 \\
\hline From $11-15$ years & 23 & 24.2 \\
\hline More than 16 years & 16 & \multirow[b]{2}{*}{$7.64 \pm 5.39$} \\
\hline \multicolumn{2}{|c|}{ Mean \& SD } & \\
\hline \multicolumn{3}{|c|}{ - Experience about ADHD } \\
\hline Yes & 22 & 23.2 \\
\hline No & 73 & 76.8 \\
\hline \multicolumn{3}{|c|}{ - Taking any workshop about ADHD } \\
\hline Yes & 6 & 6.3 \\
\hline No & 89 & 93.7 \\
\hline
\end{tabular}

Table1, presents personal characteristics of teachers under the study, it was found that the majority (95.8\%) of them were married and more than half of them $(55.8 \%)$ were male with mean age $45.82 \pm 8.35$ years. Regarding level of education most of the studied teachers $(90.5 \%)$ had Bachelor's degree and about one third of them had experience $<5$ years. Also, the majority of the studied teachers had neither experience nor workshops about ADHD (76.8\% and $93.7 \%)$ respectively.

Table 2. Mean knowledge scores of the studied teacher's regarding ADHD pre and post educational program (n $=95)$

\begin{tabular}{|c|c|c|c|c|c|}
\hline \multirow{2}{*}{\multicolumn{2}{|c|}{ Total }} & Pre-program & Post- program & \multirow[t]{2}{*}{ Paired t test } & \multirow[t]{2}{*}{ P value } \\
\hline & & Mean \pm SD & Mean \pm SD & & \\
\hline & $\begin{array}{l}\text { Natures, causes and outcomes of } \\
\text { ADHD }\end{array}$ & $12.8632 \pm 4.57935$ & $21.9263 \pm 4.15201$ & -16.459 & $<0.001 * *$ \\
\hline$\bullet$ & Symptoms/diagnosis of ADHD & $9.1263 \pm 3.15299$ & $12.7579 \pm 2.74721$ & -8.377 & $<0.001 * *$ \\
\hline$\bullet$ & Treatment of ADHD & $10.8842 \pm 4.67648$ & $16.7368 \pm 2.20353$ & -10.356 & $<0.001 * *$ \\
\hline & Total knowledge & $32.8737 \pm 10.88259$ & $51.4211 \pm 5.65230$ & 15.31 & $<0.001 * *$ \\
\hline
\end{tabular}

** Highly statistically significant differences

Mean score of the studied teachers' knowledge about ADHD was represents in Table 2. There were statistically significant differences between the mean teachers' knowledge scores of pre-program and post-program (P $<0.001$ ). 


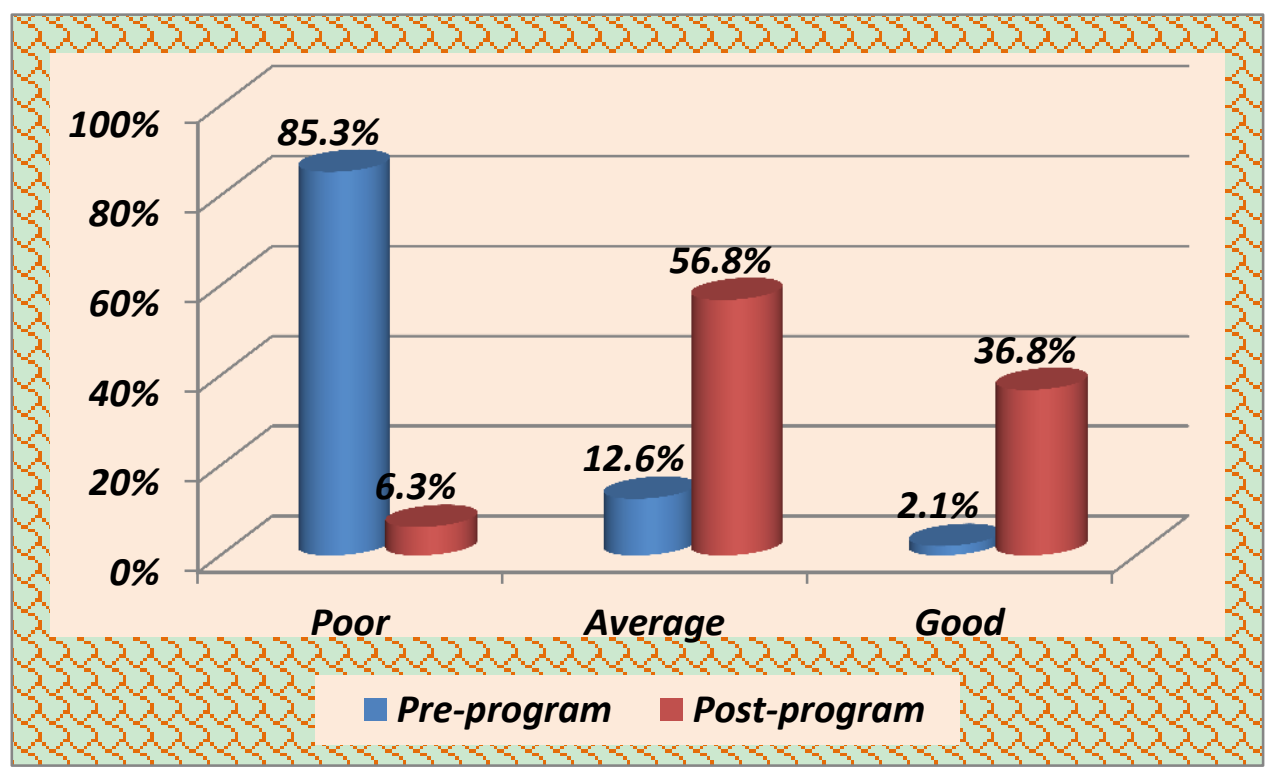

Figure 1. Distribution of studied teachers regarding to their total knowledge score about ADHD pre and post educational program $(\mathrm{n}=95)$

Figure 1 displays that, before the program; $85.3 \%$ of the studied participants had poor total knowledge, $12.6 \%$ had average total knowledge and $2.1 \%$ had good total knowledge scores regarding ADHD, while after the program; good total knowledge scores increased to $36.8 \%$ and average total knowledge decreased to $56.8 \%$.

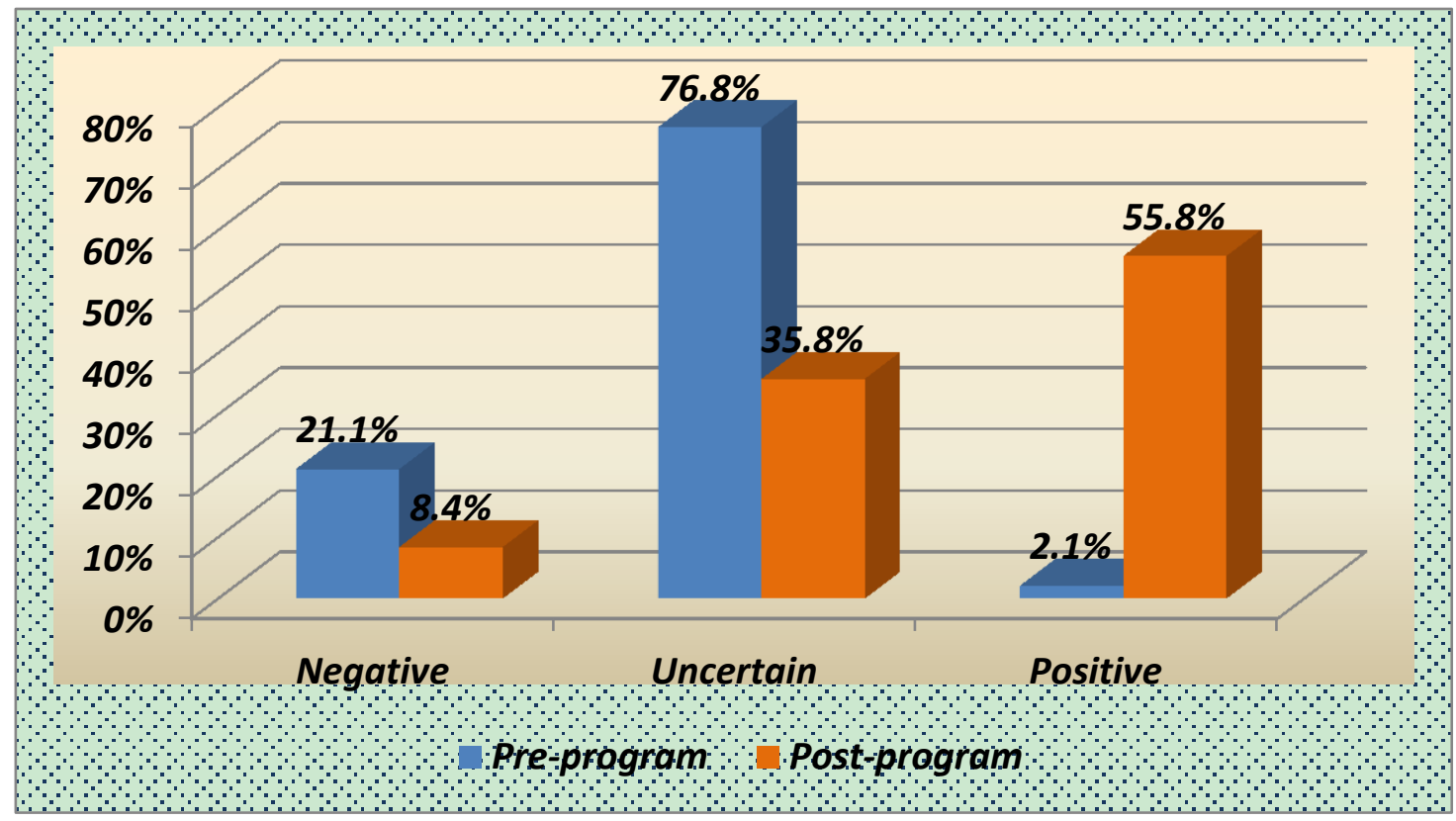

Figure 2. Level of teachers' attitude regarding ADHD at pre and post educational program $(\mathrm{n}=95)$

The level of teachers' attitude regarding ADHD at pre and post educational program was illustrated in figure 2. It is obvious that, before the program; only $2.1 \%$ of the studied participants had positive attitude and the majority of them $(76.8 \%)$ had uncertain attitude about ADHD compared to $55.8 \%$ for positive attitude and $35.8 \%$ for uncertain attitude after the program. 
Table 3. Mean classroom management techniques scores of the studied teacher's regarding ADHD pre and post educational program $(\mathrm{n}=95)$

\begin{tabular}{lllrl}
\hline \multicolumn{1}{c}{ Items } & Pre-program & Post- program & \multirow{2}{*}{ Paired t test } & P value \\
\cline { 2 - 3 } & \multicolumn{1}{c}{ Mean \pm SD } & Mean \pm SD & & \\
\hline Seating in classroom & $1.3053 \pm .46296$ & $2.0000 \pm .00000$ & -14.626 & $<0.001^{* *}$ \\
Educational interventions & $1.2316 \pm .42408$ & $1.9789 \pm .14432$ & -16.676 & $<0.001^{* *}$ \\
Assistive technology & $1.2105 \pm .40985$ & $1.9789 \pm .14432$ & -17.661 & $<0.001^{* *}$ \\
Academic and social improvement & $1.0632 \pm .59806$ & $1.9789 \pm .14432$ & -14.560 & $<0.001^{* *}$ \\
Setting of behavioral expectation & $1.2316 \pm .42408$ & $1.9789 \pm .14432$ & -15.079 & $<0.001^{* *}$ \\
Time given for test & $1.0632 \pm .59806$ & $1.9158 \pm .27918$ & -11.637 & $<0.001^{* *}$ \\
Learning expectations & $1.2105 \pm .40985$ & $1.9579 \pm .20189$ & -13.868 & $<0.001^{* *}$ \\
Classroom rules & $1.2105 \pm .40985$ & $1.9368 \pm .24454$ & -14.348 & $<0.001^{* *}$ \\
Repetition of directions & $1.2421 \pm .43063$ & $1.9579 \pm .20189$ & -14.005 & $<0.001^{* *}$ \\
Class work broken into units & $1.1579 \pm .65746$ & $1.9579 \pm .20189$ & -12.742 & $<0.001^{* *}$ \\
Token reinforcement & $1.1789 \pm .66810$ & $2.0000 \pm .00000$ & -11.978 & $<0.001^{* *}$ \\
Communication as intervention & $1.1789 \pm .66810$ & $1.9368 \pm .24454$ & -11.706 & $<0.001^{* *}$ \\
Ignore disruptive behavior & $1.0632 \pm .59806$ & $1.9158 \pm .27918$ & -14.257 & $<0.001^{* *}$ \\
Total strategy & $16.2211 \pm 4.76954$ & $25.4947 \pm 1.27056$ & -17.171 & $<0.001^{* *}$ \\
\hline
\end{tabular}

** Highly Statistically significant differences

Table 3 indicates statistically significant improvement were revealed in mean teacher's perception of classroom management techniques toward child with ADHD, were much higher in the post program implementation $25.4947 \pm 1.27056$ compared to preprogram $16.2211 \pm 4.76954(\mathrm{P}<0.001)$.

Figure 3. Teacher's perception of classroom management techniques levels toward child with ADHD at pre and

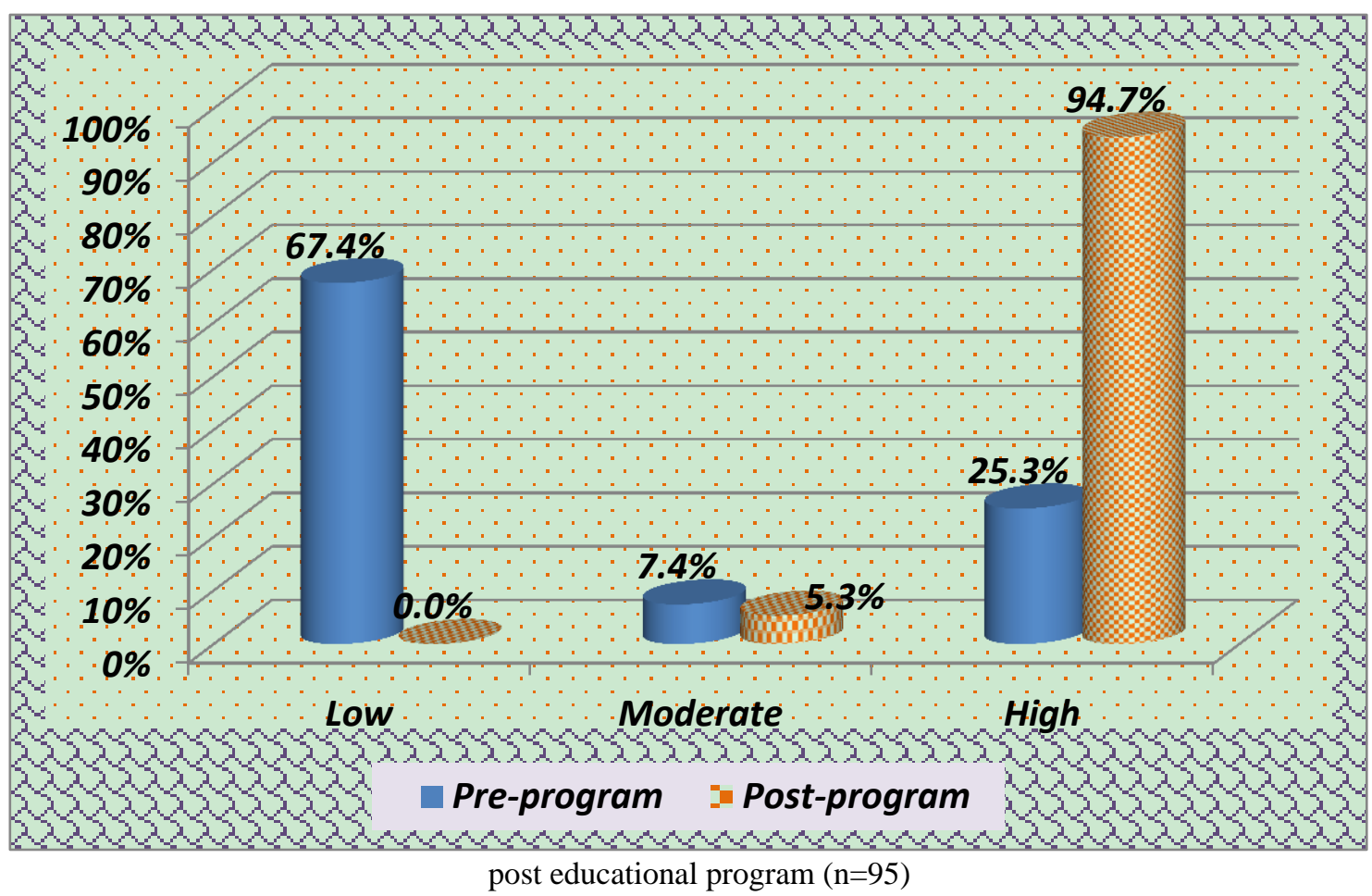

Figure 3 displays teacher's perception of classroom management techniques levels toward child with ADHD. It was noticed that before the program more than two thirds of teachers $(67.4 \%)$ had low level of perception of classroom management techniques, $7.4 \%$ had moderate perception and $25.3 \%$ had high perception, while after the program $94.7 \%$ of the teachers had high perception, 5.3\% had moderate perception and none of them had low level. 
Table 4. Relation between teacher's knowledge about ADHD post educational program and personal characteristics $(\mathrm{n}=95)$

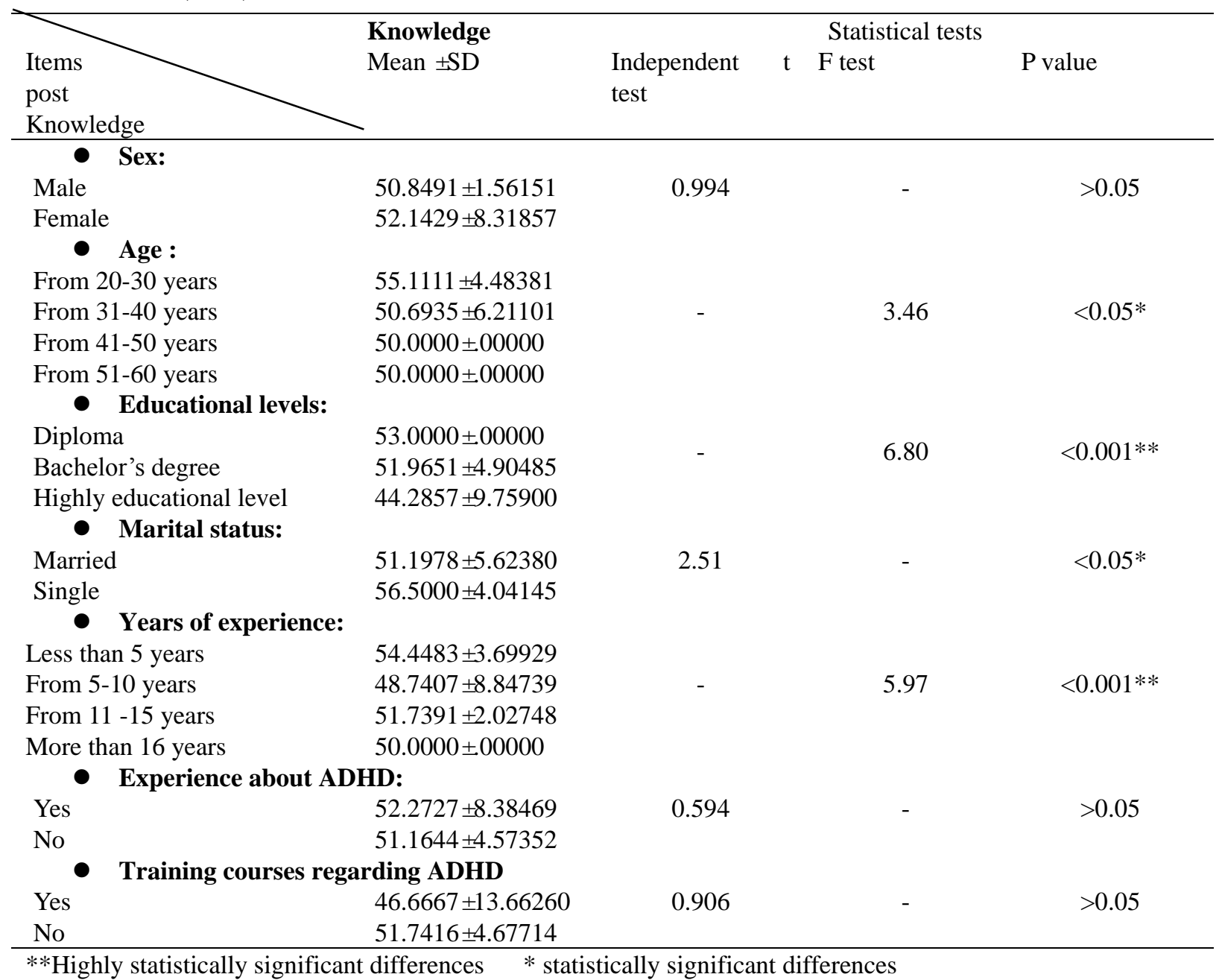

Table 4, indicates a highly statistical significant relation between total knowledge score of the studied teachers educational level and years of experience about ADHD in addition statistical significant relation between total knowledge score and their age and marital status at the post-program.

Table 5. Relation between teacher's attitude about ADHD post educational program and personal characteristics $(\mathrm{n}=95)$

\begin{tabular}{llccc}
\hline Post Attitude & $\begin{array}{l}\text { Attitude } \\
\text { Mean } \pm \text { SD }\end{array}$ & $\begin{array}{l}\text { Statistical tests } \\
\text { Independent t test }\end{array}$ & F test & P value \\
\hline Sex: & $114.5283 \pm 7.50283$ & 22.64 & - & $<0.001^{* *}$ \\
$\quad$ Male & $79.6190 \pm 7.42754$ & & & \\
Female & & & & \\
Age : & $85.5556 \pm 13.66930$ & & 5.85 & $<0.05^{*}$ \\
From 20-30 years & $100.3871 \pm 18.93505$ & - & & \\
From 31-40 years & $107.0000 \pm 18.97367$ & & \\
From 41-50 years & $116.0000 \pm .00000$ & & & \\
From 51-60 years & & & & \\
$\quad$ Educational levels: & $81.0000 \pm .00000$ & & & \\
Diploma & $99.4651 \pm 19.14446$ & - & & \\
Bachelor's degree & $99.7143 \pm 17.89520$ & & & \\
$\quad$ Highly educational level & & & & \\
\hline
\end{tabular}




\begin{tabular}{|c|c|c|c|c|}
\hline \multicolumn{5}{|l|}{ Marital status: } \\
\hline Married & $99.8901 \pm 18.96690$ & 9.50 & - & $<0.001 * *$ \\
\hline Single & $81.0000 \pm .00000$ & & & \\
\hline \multicolumn{5}{|l|}{ Year of experience: } \\
\hline Less than 5 years & $86.6207 \pm 15.74895$ & & & \\
\hline From $5-10$ years & $90.9630 \pm 18.55446$ & - & 24.48 & $<0.001 * *$ \\
\hline From $11-15$ years & $112.6087 \pm 11.23606$ & & & \\
\hline More than 16 years & $116.0000 \pm .00000$ & & & \\
\hline \multicolumn{5}{|c|}{ Experience about ADHD: } \\
\hline Yes & $79.7273 \pm 8.08397$ & 9.46 & - & $<0.001 * *$ \\
\hline No & $104.9315 \pm 17.33360$ & & & \\
\hline \multicolumn{5}{|c|}{ Taking any workshop about ADHD: } \\
\hline Yes & $78.0000 \pm 2.36643$ & 10.19 & - & $<0.001 * *$ \\
\hline No & $100.5169 \pm 18.72839$ & & & \\
\hline
\end{tabular}

Table 5 shows a highly statistical significant relation between total attitude score of the studied teachers sex, marital status, years of experience, their previous experience and history of taking training courses about ADHD. Moreover statistical significant relation between total attitude score and their age at the post program.

Table 6. Relation between teacher's perception of classroom management techniques toward child with ADHD post educational program and personal characteristics $(n=95)$

\begin{tabular}{|c|c|c|c|c|}
\hline \multirow{2}{*}{ Items post Strategy } & \multirow{2}{*}{$\begin{array}{l}\text { Strategy } \\
\text { Mean } \pm \text { SD }\end{array}$} & \multicolumn{3}{|c|}{ Statistical tests } \\
\hline & & Independent $\mathrm{t}$ test & F test & $P$ value \\
\hline \multicolumn{5}{|l|}{ Sex: } \\
\hline Male & $26.0000 \pm .00000$ & 4.30 & - & $<0.001 * *$ \\
\hline Female & $24.8571 \pm 1.71893$ & & & \\
\hline \multicolumn{5}{|l|}{ Age : } \\
\hline From $20-30$ years & $25.5556 \pm .98352$ & & & \\
\hline From $31-40$ years & $25.4194 \pm 1.44345$ & - & 0.365 & $>0.05$ \\
\hline From $41-50$ years & $25.6000 \pm .84327$ & & & \\
\hline From 51-60 years & $26.0000 \pm .00000$ & & & \\
\hline \multicolumn{5}{|l|}{ Educational levels: } \\
\hline Diploma & $26.0000 \pm .00000$ & & & \\
\hline Bachelor's degree & $25.5814 \pm 1.02286$ & - & 3.15 & $<0.05^{*}$ \\
\hline Highly educational level & $24.2857 \pm 2.92770$ & & & \\
\hline \multicolumn{5}{|l|}{ Marital status: } \\
\hline Married & $25.4725 \pm 1.29392$ & 3.89 & - & $<0.001 * *$ \\
\hline Single & $26.0000 \pm .00000$ & & & \\
\hline \multicolumn{5}{|l|}{ Years of experience: } \\
\hline Less than 5 years & $25.1034 \pm 1.39757$ & & & \\
\hline From 5-10 years & $25.1852 \pm 1.75493$ & - & 3.82 & $<0.05^{*}$ \\
\hline From $11-15$ years & $26.0000 \pm .00000$ & & & \\
\hline More than 16 years & $26.0000 \pm .00000$ & & & \\
\hline \multicolumn{5}{|l|}{ Experience about ADHD: } \\
\hline Yes & $24.5455 \pm 2.01724$ & 2.81 & - & $<0.001 * *$ \\
\hline No & $25.7808 \pm .74994$ & & & \\
\hline \multicolumn{5}{|c|}{ Taking any workshop about ADHD: } \\
\hline Yes & $24.0000 \pm 3.09839$ & 1.25 & - & $>0.05$ \\
\hline No & $25.5955 \pm 1.00814$ & & & \\
\hline
\end{tabular}

**highly statistically significant differences $\quad *$ statistically significant differences

Table 6, indicates a highly statistical significant relation between total strategy management score of the studied teachers sex, marital status and their previous experience about ADHD. Moreover statistical significant relation between total strategy management score and their educational qualification and years of experience at the post-intervention phase. 
Table 7. Correlations between teacher's knowledge, attitude, and perception of classroom management techniques $(\mathrm{n}=95)$

\begin{tabular}{|c|c|c|c|c|c|c|}
\hline \multirow[b]{2}{*}{ Items } & \multicolumn{2}{|c|}{ Knowledge } & \multicolumn{2}{|c|}{ Attitude } & \multicolumn{2}{|c|}{ Strategy } \\
\hline & $\mathbf{R}$ & P value & $\mathbf{R}$ & P value & $\mathbf{R}$ & P value \\
\hline Knowledge & - & & .055 & .594 & $.223^{*}$ & .030 \\
\hline Attitude & .055 & .594 & - & & $.447^{* *}$ & .000 \\
\hline $\begin{array}{l}\text { Perception of classroom management } \\
\text { techniques (strategy) }\end{array}$ & $.223^{*}$ & .030 & $.447^{* *}$ & .000 & - & \\
\hline
\end{tabular}

*. Correlation is significant at the 0.05 level (2-tailed). **. Correlation is significant at the 0.01 level (2-tailed).

Table 7 shows the correlation between teacher's knowledge, attitude, and perception of classroom management techniques regarding ADHD. Statistically significant positive association was found among the studied teachers' knowledge, attitude and class room management strategies at post intervention phase, the teachers' knowledge increase, positively teachers' attitude and classroom management techniques of ADHD increase.

\section{Discussion}

The study aimed to evaluate the effect of educational program on knowledge, attitude and classroom management technique among elementary school teachers in Hail City towards attention deficit hyperactivity disorder. According to personal characteristics of teachers under the study, it was observed that, the mean age of participants was (45.82 \pm 8.35 ), More than three quadrant of them had no experience about ADHD, as well as, most of them not taking any workshops about ADHD. These finding is supported by Muanprasart et al., (2014), who found that mean age in year were $(45.01+12.36)$. The majority of participants have never been taught about or trained on ADHD.

Regarding education, the majority of sample had Bachelor's degree and less than one third of them had less than five years of experience as well as, These finding was congruent with Guerra \& Brown (2012), who stated that the majority of surveyed teachers selected bachelor's degree as their highest level of education, and the response category with the highest frequency of responses was one to five years of teaching experience (29\%) and no coursework related to ADHD.

Concerning the teachers' knowledge about ADHD, the present study indicating that the knowledge is reached to highest mean $(51.4211 \pm 5.65230)$ post program, there was highly statistically significant differences in total knowledge between pre and post program. These finding was in the same line Williams et al., (2013), with who said that the mean post-test knowledge score (13.7) was higher than mean pretest score (5.4). Also, Park \& Park (2017) in their study about development and effects of an instructional coaching program regarding children with attention deficit hyperactivity disorder for elementary school teachers, found that The experimental group showed a significant improvement in teacher's knowledge regarding ADHD ( $\mathrm{F}=7.16, \mathrm{p}=.010)$ and the implementation of instructional interventions $(\mathrm{F}=4.29, \mathrm{p}=.043)$ improved. The instructional coaching program was well structured and significantly improved teachers' knowledge. As well, Lopez-Lopez et al., (2018), stated that teachers with training in ADHD are more knowledgeable and more confident about their abilities when it comes to teaching children with ADHD.

As regards teacher's total knowledge levels about ADHD pre and post educational program, before the program; most of the studied participants had poor total knowledge regarding ADHD, while after the program; more than one third had good total knowledge scores. This is may be due to the effect of educational program on teachers' knowledge. These results are similar to those of by Aly et al., (2015), who reported that the total score of teachers' knowledge about ADHD, indicated that more than three quarter of teachers (76.1\%) had unsatisfactory knowledge.

The relation between teachers' knowledge post educational program and personal characteristics. The results of the present study indicates a highly statistical significant relation between total knowledge score of the studied teachers educational level and years of experience about ADHD in addition no statistical significant relation between total knowledge score and experience about ADHD at the post- program. This may be due to more than three quadrant of teachers don't have previous experience about ADHD children .These findings were contradicted with Perold et al., (2010); Patidar et al., (2016), who stated that overall knowledge of ADHD, as measured by KADDS, was unrelated to the years of general teaching experience they have $(p>0.05)$, and Overall knowledge of ADHD was also positively related to teachers' exposure to ADHD as childhood disorder. But in the same line with the findings of Sciutto et al., (2000), indicating that teachers in the United States with 
more years of teaching experience obtained higher scores than teachers with less teaching experience.

Regarding the teachers' attitude toward ADHD, the present study revealed that, about one fifth of the studied participants had negative attitude about ADHD before the program. While more than half of them have positive attitude. These findings were in the same line with Lasisi et al., (2017), in their study about effectiveness of attention deficit hyperactivity disorder training program on the knowledge and attitudes of primary school teachers towards pupil found that training program significantly improved the knowledge and attitudes of the teachers in the intervention group towards ADHD. As well, Bhasin et al., (2018), said that teaching programs were effective in improving knowledge and attitude among primary school teachers regarding ADHD and LD.

The relation between teacher's attitude post educational program and personal characteristics at Hail elementary school, the results of the present study presents that there were a highly statistical significant relation between total attitude score of the studied teachers and their previous experience and history of taking training courses about ADHD. This finding were consistent with Doukanari (2015), who said that teachers who shared experiences with inattentive students expressed more favorable attitudes towards them and their education in mainstream classrooms.

Concerning teacher's perception of classroom management techniques toward child with ADHD, the present study revealed that there were statistically significant differences in total teachers' perception between pre and post program. This finding was consistent with Shehata et al., (2016), who stated that there were statistically significant differences between pre-and post-assessment regarding teachers' behavioral management strategies in all strategies except using planned ignoring strategy.

The present study illustrates a highly significant positive association among the studied teachers' total knowledge, attitude, and perception of classroom management techniques at Hail elementary school. The present study illustrates a highly significant positive association among the studied teachers' total knowledge, attitude and class room management strategies total score at post educational program. This result could be interpreted as improving teachers knowledge is positively improve teacher's attitude and classroom management technique of ADHD. These findings were in the same line with Shehata et al., (2016), who stated that that a statistically significant difference between whole pre-and post-mean scores of teachers regarding all dependent studied variables (knowledge, attitude and behavioral management strategies) with children with ADHD.

\section{Conclusion}

The current study concluded that mean scores of knowledge of the studied subjects were significantly increased after implementing the educational program. As well as, the program was effective in improving teachers' knowledge, attitude, and classroom management technique regarding ADHD.

\section{Recommendations}

Based on the results of the study, the following recommendations are suggested :

1. Increasing awareness about ADHD and importance of adopting class room management technique in order to deal children with ADHD through health education programs to teachers were needed.

2. Acquaint all teachers with updated information regarding ADHD knowledge including classroom management technique.

\section{References}

ALBashtawy, M., Batiha, A., Tawalbeh, L., Tubaishat, A., \& AlAzzam, M. (2015). Self-medication among school students. Journal of School Nursing, 31(2), 110-116. https://doi.org/10.1177/1059840514554837

Aly, S., Mohammed, F., \& Ahmed, Z. (2015). Teachers' perception and attitudes toward attention deficit hyperactivity disorder in primary schools at Assiut city. AAMJ, 13(4), 171.

American Psychiatric Association. (2013). Diagnostic and statistical manual of mental disorders (5th ed.). Arlington, VA: American Psychiatric Association. https://doi.org/10.1176/appi.books.9780890425596

Anderson, D., Ellen Watt, S., Noble, W., \& Shanley, D. (2012). Knowledge of attention deficit hyperactivity disorder (ADHD) and attitudes toward teaching children with ADHD: The role of teaching experience. Psychology in School, Wiley periodicals, Inc., 49(6), 511-552.

Arnett, A., MacDonald, B., \& Pennington, B. (2013). Cognitive and behavioural indicators of ADHD symptoms prior to school age. Journal of Child Psychology and Psychiatry, 54(12), 1284-1294. https://doi.org/10.1111/jcpp.12104

Barkley, R.A. (2014). Attention deficit hyperactivity disorder: A handbook for diagnosis and treatment (4th ed.). 
New York, NY: Guilford.

Bascuas, K. (2016). School nurses and nurse practitioners partner to address ADHD. Retrieved from https://associationsnow.com/2016/02/school-nurses-and-nurse-practitioners-partner-to-address-adhd/

Bhandari, S. (2017). Attention Deficit Hyperactivity Disorder: Causes of ADHD, WebMD Medical Reference. Retrieved from https://www.webmd.com/add-adhd/guide/adhd-causes

Bhasin, V., Srinivasan, P., \& Deaver, U. (2018, August). Effectiveness of Various Teaching Programs on Knowledge and Attitude Regarding Attention Deficit Hyperactivity Disorder (ADHD) and Learning Disabilities (LD) of Children among Primary School Teachers: A Systematic Review. International Journal of Health Sciences and Research, 8(8).

Bradshaw, L., \& Madeeha, K. (2013). Teacher knowledge, training and acceptance of students with ADHD in their classrooms: Qatar case study. Near and Middle Eastern Journal of Research in Education. https://doi.org/10.5339/nmejre.2013.5

Doukanari, M. (2015, January). Attention Deficit Hyperactivity Disorder (ADHD): Cypriot elementary school teachers' knowledge, attitudes and in-service training (INSET). Hillary Place Papers (2nd ed.). University of Leeds.

DuPaul, G., \& Weyandt, L. (2006). School-based intervention for children with Attention Deficit Hyperactivity Disorder: Effects on academic, social, and behavioural functioning. International Journal of Disability, Development and Education, 53(2), 161-176. https://doi.org/10.1080/10349120600716141

Guerra, F., \& Brown, M. (2012). Teacher Knowledge of Attention Deficit Hyperactivity Disorder Among Middle School Students in South Texas, 36(3). Retrieved from https://files.eric.ed.gov/fulltext/EJ989795.pdf

HADD support Group. (2017). Teaching and Managing Children With ADHD. Ireland. Retrieved from http://www.hadd.ie/article/teaching-and-managing-children-adhd

Herbert, J., Crittenden, K., \& Dalrymple, K. (2004). Knowledge of Social Anxiety Disorder Relative to Attention Deficit Hyperactivity Disorder Among Educational Professionals. Journal of Clinical Child and Adolescent Psychology, 33, 366-372. https://doi.org/10.1207/s15374424jccp3302_18

Jimoh, M. (2014). Knowledge and Attitudes towards Attention Deficit Hyperactivity Disorder among Primary School Teachers in Lagos State, Nigeria. Advances in Life Science and Technology, 23, 9.

Khamaiseh, A., \& ALBashtawy, M. (2015). Prevalence of obesity and physical inactivity behaviors among nursing students in Mutah University, Jordan. World Journal of Medical Sciences, 12(2), 95-102.

Krull, K. (2017). Attention deficit hyperactivity disorder in children and adolescents: Clinical features and diagnosis. Retrieved from https://www.uptodate.com/.../attention-deficit-hyperactivity-disorder

Lasisi, D., Ani, C., Lasebikan, V., Sheikh, L., \& Omigbodun, O. (2017). Effect of attention-deficit-hyperactivity-disorder training program on the knowledge and attitudes of primary school teachers in Kaduna, North West Nigeria. Child Adolesc Psychiatry Ment Health., 11, 15. https://doi.org/10.1186/s13034-017-0153-8

Lopez-Lopez, A., Lopez-Lafuente, A., Eiris-Punal, J., Mulas, F., \& Cardo, E. (2018). A study of primary school teachers' knowledge of attention deficit hyperactivity disorder. Retrieved from https://www.unboundmedicine.com/medline/citation/29516464/(astudy-of-teachers;-knowledge-of-attentio n-deficit-hyperactivity-disorder

Muanprasart, P., Traivaree, C., Arunyanart, W., \& Teeranate, C. (2014). Knowledge of Attention Deficit Hyperactivity Disorder and Its Associated Factors among Teachers in 3 Large, Primary Schools in PhraNakorn Sri Ayutthaya Province, Thailand. J Med Assoc Thai, 97(Suppl. 2), S107-S114.

National Institution of Mental Health. (2016). Attention Deficit Hyperactivity Disorder, a component of the U.S. Department of Health and Human Service. Retrieved from https://www.nimh.nih.gov/health/...hyperactivity...adhd/index.shtml

Park, S., \& Park, W. (2017, June). Development and Effects of an Instructional Coaching Program Regarding Children with Attention Deficit Hyperactivity Disorder for Elementary School Teachers. J. Korean AcadNurs., 47(3), 305-318. https://doi.org/10.4040/jkan.2017.47.3.305

Patidar, P., Chaudhary, J., Parikh, N., Shah, N., \& Darji, V. (2016, December). Knowledge of attention deficit hyperactivitydisorder (ADHD) among primary school teachers of Ahmedabad. Indian Journal of Applied 
Research, 6(12).

Perold, M., Louw, C., \& Kleynhans, S. (2010). Primary school teachers' knowledge and misperceptions of attention deficit hyperactivity disorder (ADHD). South African Journal of Education, EASA, 30, 457-473.

Raggi, V., \& Chronis A. (2006). Interventions to address the academic impairment of children and adolescents with ADHD. Clinical Child and Family Psychology Review, 9(2), 85-111. https://doi.org/10.1007/s10567-006-0006-0

Sciutto, M., Terjesen, M., \& Bender Frank, A. (2000).Teachers' Knowledge and Misperceptions of Attention-Deficit/Hyperactivity Disorder. Psychology in the Schools, 37(2), 115-122.

Shehata, A., Mahrous, E., Farrag, E., \& Hassan, Z. (2016). Effectiveness of structured teaching program on knowledge, attitude, and management strategies among teachers of primary school toward children with attention deficit hyperactivity disorder. IOSR Journal of Nursing and Health Science, 5(6), 29-37.

Soroa, M., Gorostiaga, A., \& Balluerka, N. (2013). Review of Tools Used for Assessing Teachers' Level of Knowledge with Regards Attention Deficit Hyperactivity Disorder (ADHD). In S. Banerjee (Ed.), Attention Deficit Hyperactivity Disorder in Children and Adolescents. https://doi.org/10.5772/50252

Thapar, A., Cooper, M., Jefferies, R., \& Stergiakouli, E. (2012, September). What causes attention deficit hyperactivity disorder?.

The Substance Abuse and Mental Health Services Administration. (2012). Identifying mental health and substance abuse problems of children and adolescents: A guide for child-serving organizations. Retrieved from

http://store.samhsa.gov/product/Identifying-Mental-Health-and-Substance-UseProblems-of-Children-and-A dolescents-A-Guidefor-Child-Serving-Organizations/SMA12-4700

Williams, A., Singh, G., \& Narayan, P. (2013). Competency of School Teachers Regarding Learning Disabilities. IOSR Journal of Nursing and Health Science (IOSR-JNHS), 2(2), 20-23. Retrieved from Www.iosrjournals.org

Youssef, M., Hutchinson, G., \& Youssef, F. (2015). Knowledge of and Attitudes toward ADHD among Teachers: Insights from a Caribbean Nation. SAGEOpen. Retrieved from http://journals.sagepub.com/doi/abs/10.1177/2158244014566761

\section{Copyrights}

Copyright for this article is retained by the author(s), with first publication rights granted to the journal.

This is an open-access article distributed under the terms and conditions of the Creative Commons Attribution license (http://creativecommons.org/licenses/by/4.0/). 